\title{
Developing a Rainfall-Based Index for Corn Crop Insurance in Isabela, Philippines
}

\author{
Kristine Dale R. Alcaide ${ }^{1}$, Mark Joseph J. Buncag, MSc ${ }^{2}$, Rizza Eve S. Mendoza, MSc ${ }^{3}$, \\ Louis Balbino U. Santos ${ }^{4}$ \\ ${ }^{1}$ Faculty, University of the Philippines Los Baños, Philippines \\ ${ }^{* 2}$ Faculty, Palawan State University San Vicente Campus, Palawan, Philippines \\ ${ }^{3}$ Research Staff, International Rice Research Institute, Philippines \\ ${ }^{4}$ MS Student, University of the Philippines Los Baños, Philippines
}

\begin{abstract}
Corn, also known as maize, is one of the most important agricultural products produced by countries worldwide. Production of this crop is highly affected by climate change, especially if the water demand is not reach. With this, a rainfall-based index for crop insurance is an instrument to help farmers lower their risks in planting.

The main objective of this study was to develop a rainfall-based index for corn crop insurance. Specifically, this study identified the threshold values for the index and estimated the probability of corn crop failure in the province of Isabela, Philippines. This study utilized Kolmogorov-Smirnov Test, Chi-Square Goodness of Fit Test, and Anderson-Darling Goodness of Fit Test to determine the probability distribution that best fits the data through Easyfit software and StatAssist, a built-in software in Easyfit to evaluate the probability of corn crop failure.

The probability of crop failure for each stage of corn growth was obtained and based from the results, low-risk planting periods were found be: May to November for early crop growth stage, April and June to September for rapid crop growth stage, May to August for reproductive stage, and April to July for maturity stage. High-risk planting periods were found to be: January to March for early crop growth stage, January to March, May, November and December for rapid crop growth stage, January, February and October to December for the reproductive stage, and January, September to December for maturity stage.
\end{abstract}

Keywords: corn crop failure, probability distribution, and planting periods

\section{Introduction}

Crop insurance is an instrument that aims to help farmers lower their risks over the impacts of climate change. It cushions them in cases of production failure. In response to climate change, climate risk insurance is being advocated. Climate risk insurance is an insurance product that covers losses due to climate-related risks (IFAD, 2011) (Schaefer and Waters, 2016). A type of climate risk insurance is Index Insurance, which is based on weather, satellite or yield. It is both objective and straightforward. There is no need to either measure the actual loss of the farmer or conduct field assessments. This way, farmers will have the liquidity required to recover and prepare for another season of farming, increasing their resiliency.

Weather Index-Based Insurance (WIBI) is an example of Index Insurance. The insurance contract in WIBI is based on weather parameters like rainfall or temperature measurements of a specific weather station at a particular period of time (IFAD, 2011). All policyholders covered by the weather station will receive payouts based on the same contract and readings at that particular weather station (Lansigan, 2015) (Neate, 2013). In the Philippines, WIBI has been implemented by the Philippine Crop Insurance Corporation (PCIC) in 2011 through pilot testing in Agusan del Sur for rice (PCIC, 2011) and expansion to Iloilo in 2014. It has also been adopted in several other countries with a high dependence on agriculture such as India and Bangladesh (IFAD, 2011) (Schaefer and Waters, 2016).

However, WIBI is limited by its heavy reliance on the availability of meteorological data (in terms of both quality and quantity), and of a consistent record of yield production (Lansigan, 2015) (Neate, 2013). In the Philippines, the PCIC only employs WIBI in areas with sufficient data, and it covers only farms within a $20-\mathrm{km}$ 
radius of the selected weather station (Lansigan, 2015). To date, WIBI is only implemented in selected provinces.

Corn, next to rice, as the most important crop in the Philippines which reached as of June 2017 at 1.33 million metric tons, $45.97 \%$ higher than the 2016 production of 0.91 million metric tons (PSA, 2017). This crop is grown in areas considered as rain-fed lowlands, usually as a follow-up crop to rice. It is also grown in upland plain and in rolling to hilly areas (Gerpacio et al., 2004). One of such areas is the province of Isabela, which is one of the top corn-producing areas in the Philippines (Gerpacio et al., 2004) (Domingo et al, 2009)

This study developed a rainfall-based index for yellow corn crop insurance in Isabela, Philippines based on PCIC requirements of (1) sufficient availability of meteorological data, and (2) availability of areas with a consistently high record of yield production. Threshold values will be estimated to identify low and highrisk planting periods for corn. Rainfall as an index is selected because of its high correlation with corn yield. Gerpacio et al. (2004) said that rainfall variations affect the corn crop more than variations in temperature. The cumulative water requirement in corn is especially important in the seedling stage (stage Ve) and in the grainfilling or reproductive stage (stage $\mathrm{Rn}$ ). A corn plant requires 4-5 $\mathrm{mm}$ of water per day, which escalates up to 6$8 \mathrm{~mm}$ per day during the grain-filling stage (Domingo et al., 2009). Water stress in these stages is likely to result in yield loss (Gerpacio et al., 2004). Specifically, this study assessed the probability of yellow corn crop failure in Isabela, Philippines in terms of identification of high or low-risk planting periods will be helpful for the local farmers or even the local government units to manage their risks related to corn production.

\section{MATERIALS AND METHODS}

\subsection{Research Locale}

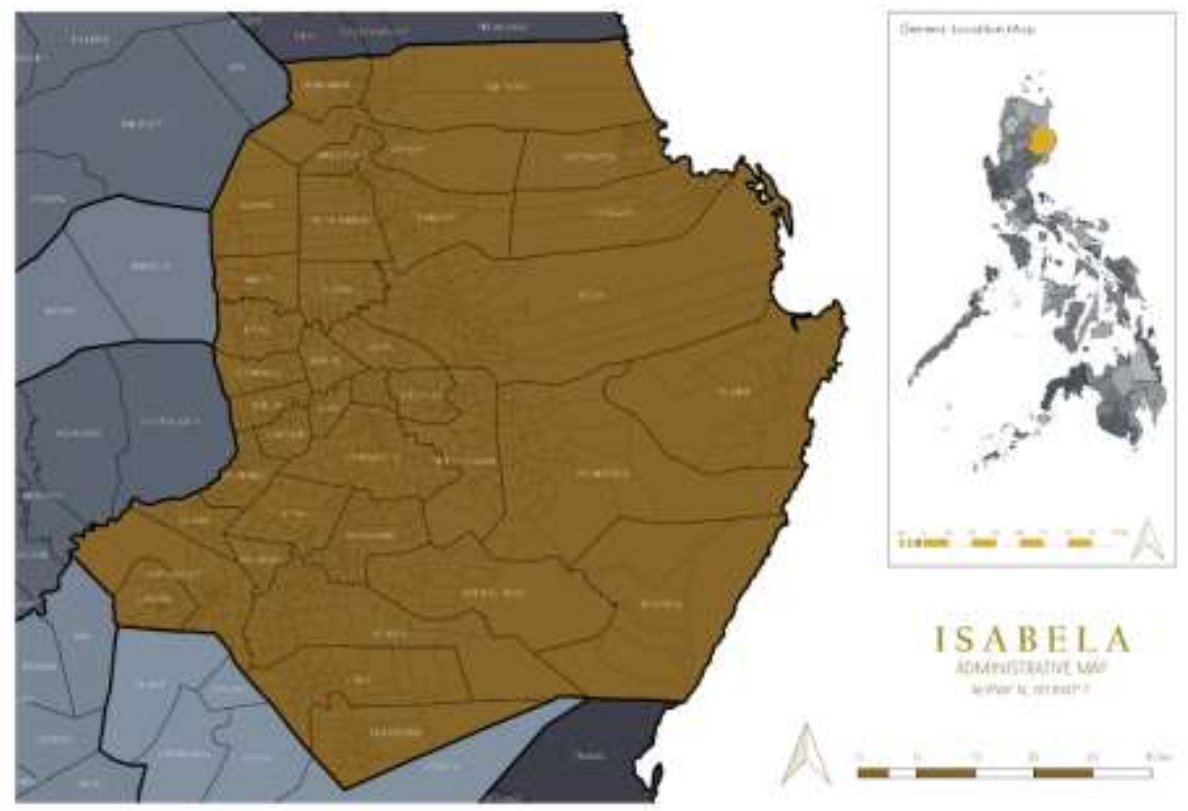

Figure 1. Map of the Philippines showing the Isabela Province

This study was conducted in Isabela, a province with a total land area of 10,655 square kilometers. Comprising more the $3 \%$ of the Philippine territory and almost $40 \%$ of the Cagayan Valley region, Isabela is the largest province on Luzon Island. It is bounded on the north by the Cagayan province; on the west by Kalinga, Mountain Province, and Ifugao; on the south by Nueva Vizcaya, Quirino, and Aurora; and on the east by the Philippine Sea and the Pacific Ocean. 


\subsection{Research Method}

This study utilized model-based estimation as a statistical tool to determine the probability of crop failure of yellow corn in the province of Isabela.

\subsubsection{Secondary Data Analysis}

This study utilized secondary data analysis. The secondary data includes yellow corn production data in the year 2016 for the province of Isabela, which was accessed from the Philippine Statistical Authority (PSA). Based on PSA (2016), Isabela has the highest corn crop production, with a volume of 1,033,271.00 metric tons. Rainfall data from 1983-2013 was acquired from the Philippine Atmospheric, Geophysical and Astronomical Services Administration (PAG-ASA).

\subsubsection{Choosing the Start of Planting Period}

From January to December, four fixed dates for each month were considered as the start of planting period: the $1^{\text {st }}, 8^{\text {th }}, 15^{\text {th }}$ and the $22^{\text {nd }}$ day. One cycle/time period of corn growth was considered.

\subsubsection{Defining Risk or The Probability of Crop Failure}

The risk or the probability of crop failure was specifically defined by considering rainfall. The probability of crop failure is when the cumulative water demand for each corn growth stage is not reached.

\subsubsection{Determining the Critical Threshold Values}

According to the Missouri University Crop Resource Guide (2017), the stages of corn development early plant growth, rapid plant growth, reproductive stage and maturity stage require $1.9 \mathrm{~mm}, 4.7 \mathrm{~mm}, 7.4 \mathrm{~mm}$, and $6.1 \mathrm{~mm}$ of water per day, respectively (see Table 1). From this, the length or the number of days of each stage of yellow corn development was multiplied to the set corresponding water requirement. The cumulative water demand for each stage became the critical threshold level of cumulative rainfall for each stage.

Table 1. Cumulative water demand for yellow corn for each crop development stage.

\begin{tabular}{|c|c|c|c|}
\hline GROWTH STAGE & DAYS & $\begin{array}{c}\text { DAILY WATER } \\
\text { REQUIREMIENT (mm) }\end{array}$ & $\begin{array}{c}\text { CUMULATIVE WATER } \\
\text { DEMAND (mm) }\end{array}$ \\
\hline Early Plant Growth & 30 & 1.90500 & 57.2 \\
\hline Rapid Plant Growth & 30 & 4.74133 & 142.2 \\
\hline Reproductive Stage & 40 & 7.36600 & 294.6 \\
\hline Maturity Stage & 20 & 6.09600 & 121.9 \\
\hline
\end{tabular}

\subsubsection{Model-Based Estimation}

Based on the historical weather data on rainfall, the probability distribution that best fits the observation for each of the growth stages (early plant growth, rapid plant growth, reproductive stage and maturity stage) for weather index was determined by using various tests in EasyFit(Mathwave Technologies, 2015), a statistical software used mainly for distribution fitting and estimating distribution parameters. 
After computing for the cumulative rainfall for each stage of each planting period of each year, the values were listed in a table with the following format:

Table 2. The data format for analysis.

\begin{tabular}{|c|c|c|c|c|c|}
\hline JAN-01 & JAN-08 & JAN-15 & JAN-22 & ... & DEC-22 \\
\hline Value_year-1 & Value_year-1 & Value_year-1 & Value_year-1 & $\ldots$ & Value_year-1 \\
\hline Value_year-2 & Value_year-2 & Value_year-2 & Value_year-2 & $\ldots$ & Value_year-2 \\
\hline$\cdots$ & $\cdots$ & $\cdots$ & $\ldots$ & $\ldots$ & $\ldots$ \\
\hline Value_year-k & Value_year-k & Value_year-k & Value_year-k & $\ldots$ & Value_year-k \\
\hline
\end{tabular}

The probability distribution that best fits the data per column was then assessed using the KolmogorovSmirnov Test, Chi-Square Goodness of Fit Test, and Anderson-Darling Goodness of Fit Test. The probability distribution that was ranked the highest using the three goodness of fit tests was then selected and used for computing the probability of crop failure through the cumulative distribution function of the selected distribution through the help of StatAssist, a built-in software in EasyFit, used mainly for estimating probabilities under different functions of the selected distribution such as the density function, cumulative distribution function, hazard function and survival function.

\section{RESULTS AND DISCUSSION}

In general, the study aimed to determine the risk of crop failure on yellow corn based on a weather index, which had been studied to be highly correlated to corn development. After the data gathering and analysis, the results below were presented.

\subsection{Total Amount of Rainfall for Each Month in Isabela from 1983 To 2013.}

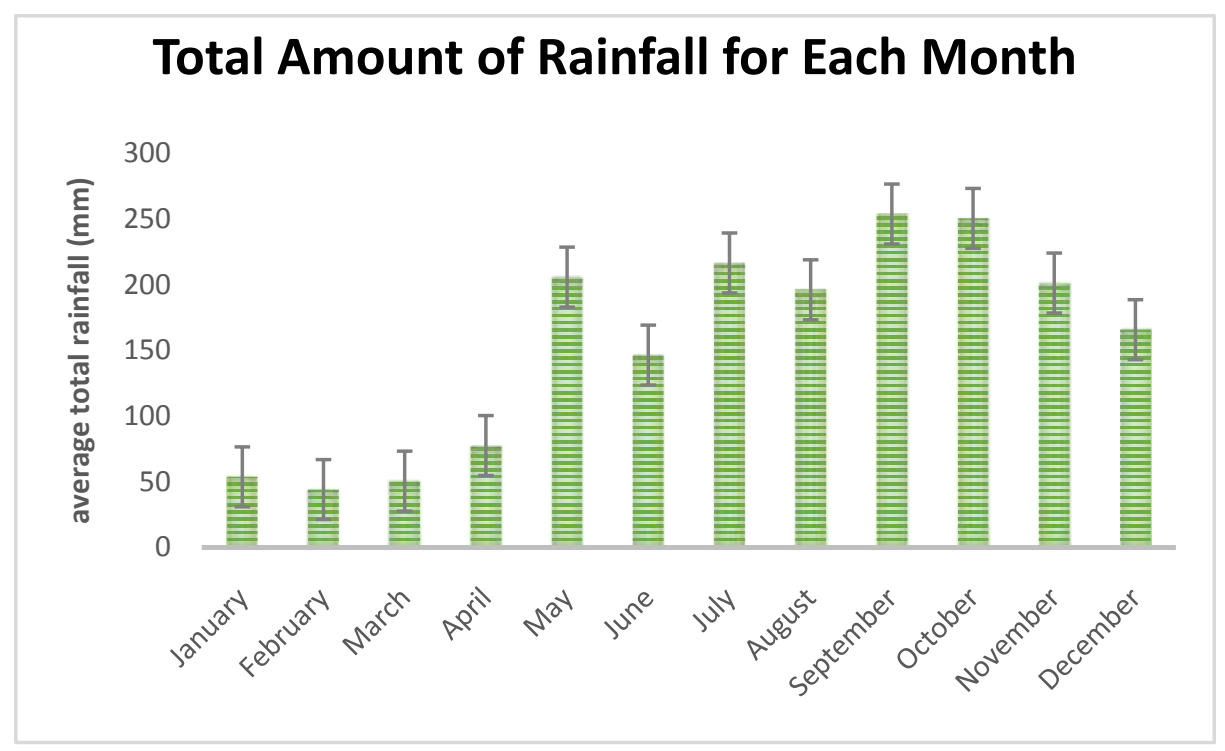

Figure 2. Mean monthly total rainfall (mm) in Isabela from 1983 to 2013 (Source: PAGASA)

Summarized in Figure 2 is the average total rainfall for each month in Isabela from 1983 to 2013. The distribution of mean monthly total rainfall, using visual inspection, is negatively skewed or skewed to the left, 
indicating that high values are on the right side of the curve. A maximum mean monthly total rainfall was observed during the month of September, while the minimum mean was observed in February.

\subsection{Probability of Crop Failure During Early Crop Growth Stage}

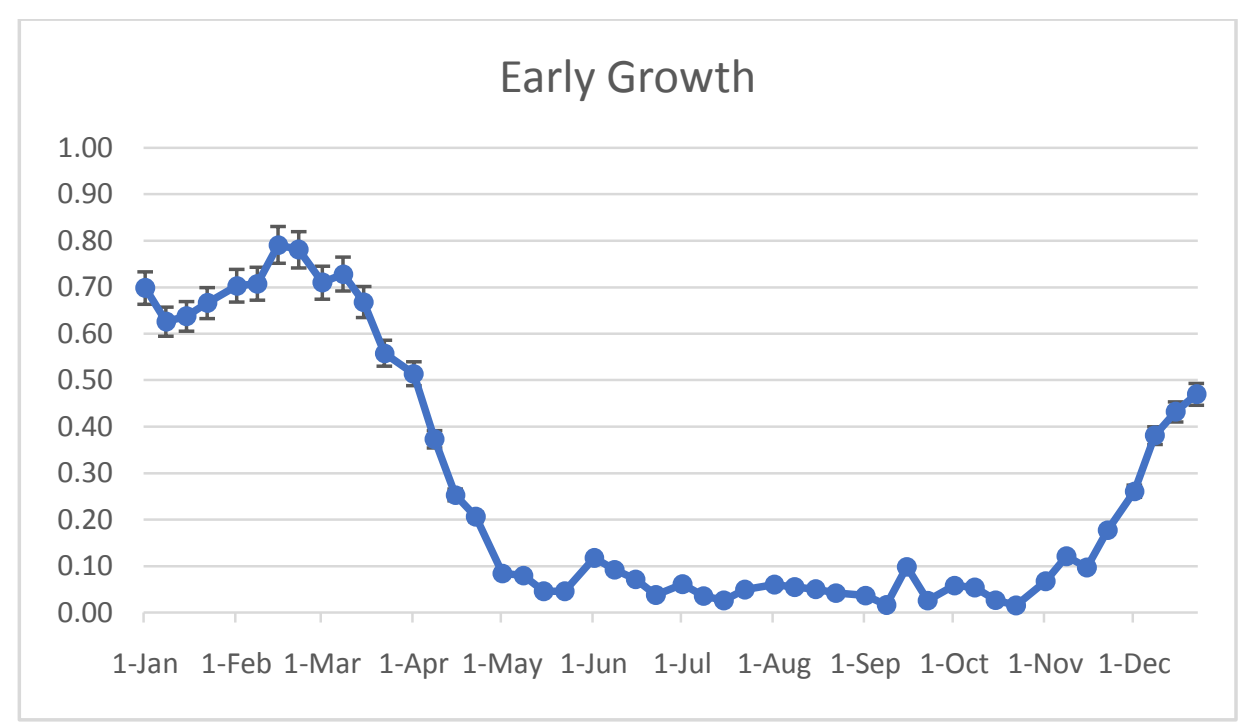

Figure 3. Estimated probability of crop failure for early crop growth stage of yellow corn due to rainfall deficit in Isabela, using historical weather data from 1983-2013.

The estimated probability of crop failure due to rainfall deficit for the early crop growth stage of yellow corn is relatively higher for the early months of the year than the latter months. The maximum risk was obtained during the month of March while the lowest is during the early weeks of September and the last weeks of October. The risk of crop failure started high in January, slightly increased during the months of February to March, started decreasing at the latter parts of March up to May, tended to be fixed from May to November, then began increasing again in December.

\subsection{Probability of Crop Failure During Rapid Crop Growth Stage}

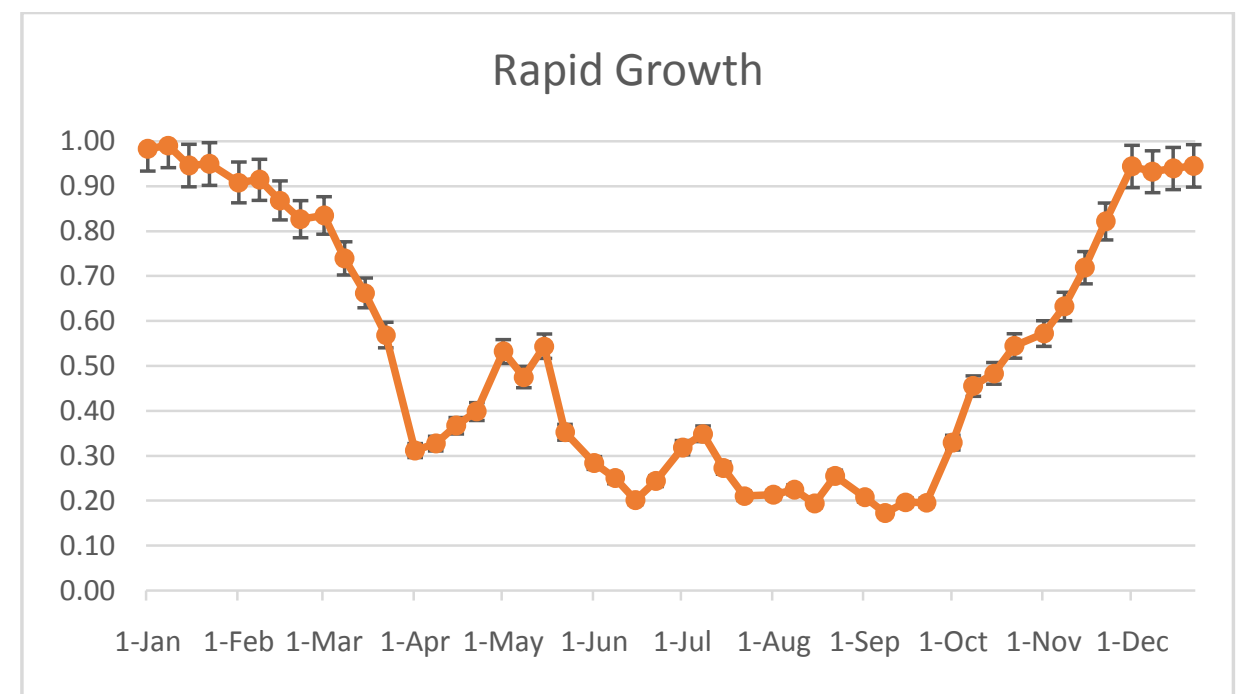

Figure 4. Estimated probability of crop failure for rapid crop growth stage of yellow corn due to rainfall deficit in Isabela, using historical weather data from 1983-2013. 
Compared with that of the early crop growth stage, the estimated probability of crop failure due to rainfall deficit for the rapid crop growth stage of yellow corn is relatively higher, though follows a similar pattern. The maximum risk was obtained during the month of January while the lowest was during the early weeks of September. The risk of crop failure started high in January, decreased for some months, and then began rising again during the month of April. Crop failure was low during the months of May to September but increased again with a steep slope from October up to the month of December. The risk of crop failure by the end of the year is almost as high as that of the first months, January and February.

\subsection{Probability of Crop Failure during Reproductive Stage}

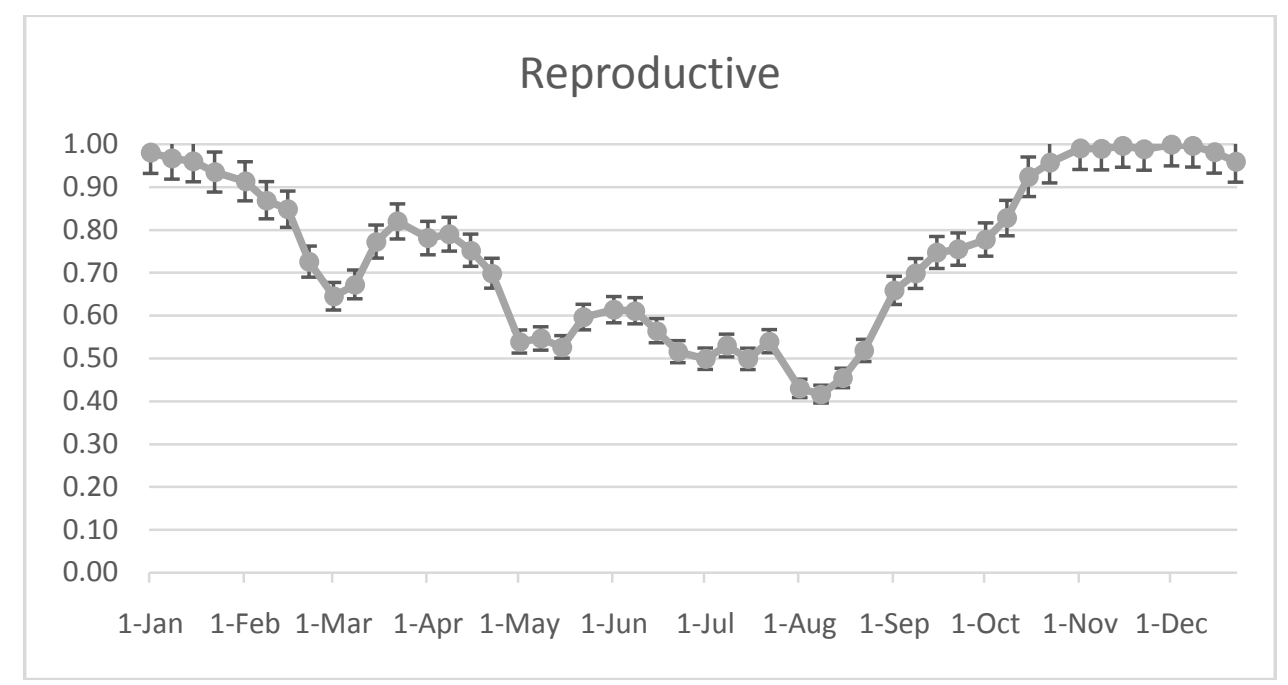

Figure 5. Estimated probability of crop failure for the reproductive stage of yellow corn due to rainfall deficit in Isabela, using historical weather data from 1983-2013.

The estimated probability of crop failure due to rainfall deficit for the reproductive stage growth stage of yellow corn is relatively higher compared to the early and rapid growth stage of corn but follows the same pattern. The maximum risk was obtained during the last two months of the year while the lowest was during the mid of August. The risk of crop failure started high at January, slightly decreased, and then started increasing again during the month of March. The probability of crop failure was relatively low during the months of May to August but rose again with a steep slope from September up to December. The risk of crop failure from the last weeks of October to December are almost fixed to one.

\subsection{Probability of Crop Failure during Maturity Stage}

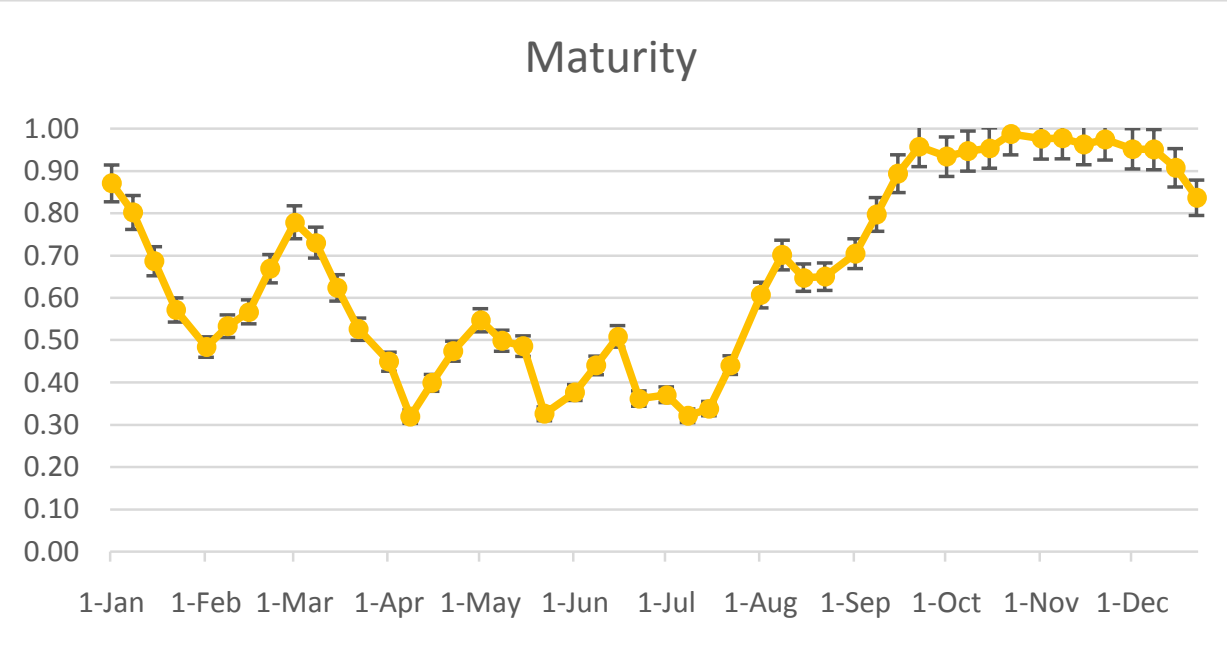

Figure 6. Estimated probability of crop failure for maturity stage of yellow corn due to rainfall deficit in Isabela, using historical weather data from 1983-2013. 
Compared to those of the first three stages of yellow corn development, the estimated probability of crop failure due to rainfall deficit for the maturity stage changes drastically over a small period of time. The risk of crop failure started high in January, decreased until the first week of February, started rising again until first week of March, and then fell again until April. The slopes of the increasing-decreasing pattern tend to be relatively low for the months of May to July, but started rising again, now with a higher slope during the last weeks of July up to the end of the year. The maximum risk was obtained during the month of October while the lowest was during the early weeks of April.

\subsection{Comparison of the Probability of Crop Failure for Each Stage}

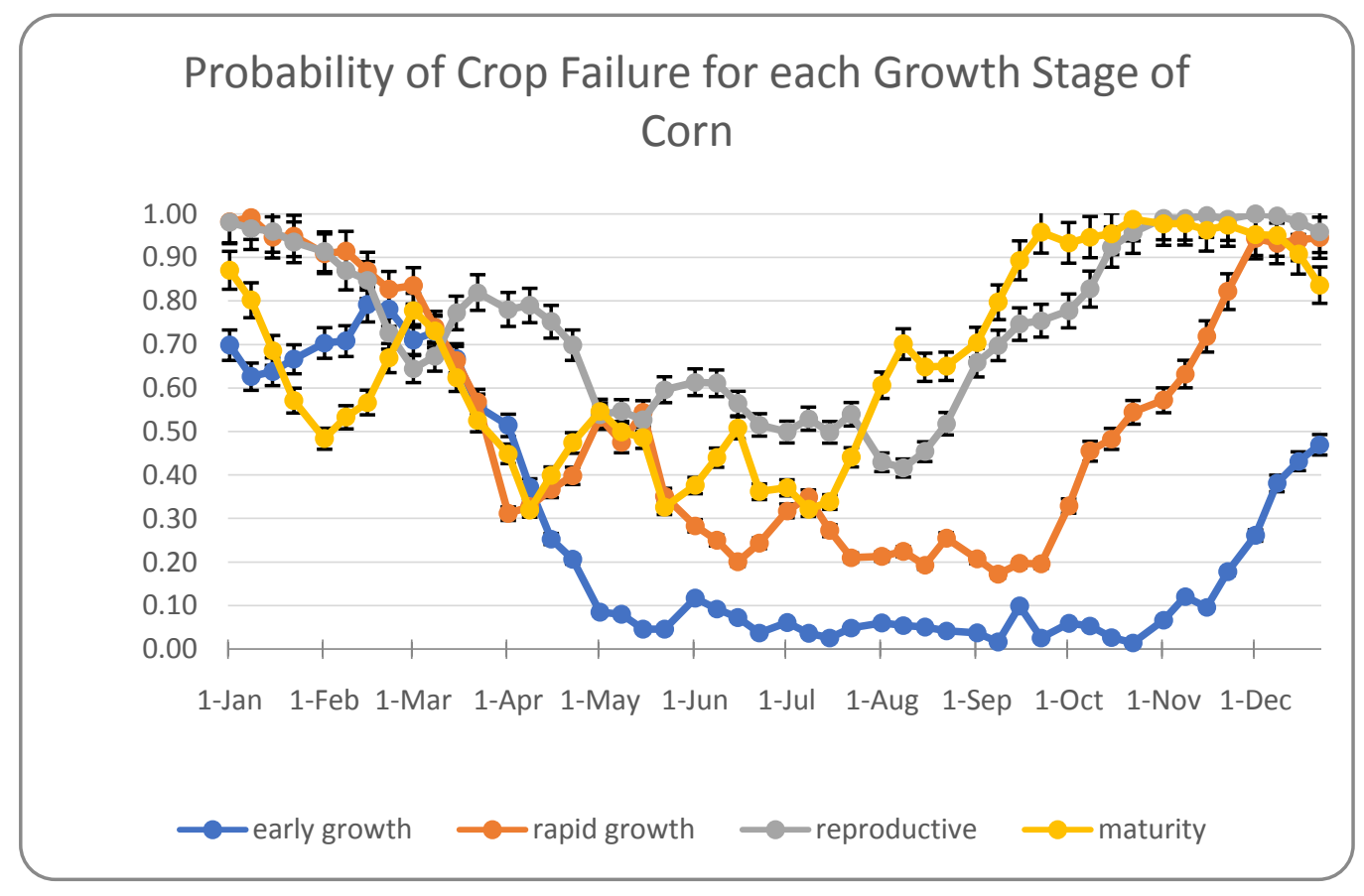

Figure 7. Estimated probability of crop failure for the four stages of yellow corn growth due to rainfall deficit in Isabela, using historical weather data from 1983-2013.

For easier comparison, the figure above was produced to summarize the risks of crop failure for each stage of the yellow corn development. The early crop growth stage tends to have the lowest risk of crop failure, compared to the three other stages. The rapid growth stage and the maturity stage follow behind in terms of risk of crop failure. The reproductive stage was observed to have high risks for almost all months of the year.

\section{CONCLUSION}

Through model-based approach, the study was able to estimate the probability of crop failure due to rainfall deficit for each stage of crop growth and development of a corn. Summarized in Tables 3 are the lowand high-risk planting periods for each growth stage based on the rainfall deficit coverage. The estimated lowrisk planting periods identified coincide with the established corn planting season in Isabela of April to June and December to January. The use of rainfall as an index for weather-index based corn insurance in Isabela can be further explored. 
Table 3. Low- and high-risk planting periods of yellow corn varieties for each crop growth stage

\begin{tabular}{|c|c|c|}
\hline \multirow{2}{*}{\begin{tabular}{|c|} 
GROWTH STAGE \\
Early Crop Growth
\end{tabular}} & $\begin{array}{c}\text { Yow-risk Planting Periods } \\
\text { May to November }\end{array}$ & $\begin{array}{c}\text { High-risk Planting Periods } \\
\text { Rapid Crop Growth }\end{array}$ \\
\hline Reproductive & $\begin{array}{c}\text { April, and June to } \\
\text { September } \\
\text { May to August }\end{array}$ & $\begin{array}{c}\text { January to March } \\
\text { December }\end{array}$ \\
\hline Maturity & April to July & $\begin{array}{c}\text { January to February, and October to } \\
\text { December }\end{array}$ \\
\hline
\end{tabular}

\section{RECOMMENDATIONS}

Based on the results of the study, the researchers make the following recommendations:

- Local farmers must be well-informed and aware of the periods where they might be exposed to a high risk of crop failure;

- Insurance companies must devise insurance products based on the estimated crop failures;

- Farmers, especially smallholder farmers, must consider availing insurance products especially when they are highly susceptible to risk;

- The local government units must facilitate farmers in availing such insurance products; and

- More studies on weather-based indices for crop insurance in other agricultural areas may be conducted.

\section{REFERENCES}

[1] Domingo, S.N, Gonzales, K.G., Mina, C.D., and Reyes,C.M. (2009) : Climate Variability, Seasonal Climate Forecast, and Corn Farming in Isabela, Philippines: a Farm and Household Level Analysis, PIDS Discussion Paper Series, No. 2009-06

[2] Gerpacio, R.V., Labios, J. D., Labios, R.V. and Diangkinay, E.I. (2004). Maize in thePhilippines: Production Systems, Constraints, and Research Priorities. Mexico, D.F.: CIMMYT.

[3] Guro, A.A. (2019). Evaluation of Corn Grain Quality as Produced by Farmers at Marantao, Lanao del Sur. International Journal of Science and Management Studies (IJSMS) Vol 2 Issue 1, 7-13.

[4] International Fund for Agricultural Development (2011). Weather Index-based Insurance in Agricultural Development: A Technical Guide.

[5] Lansigan, F.P., (2015). Implementation Issues in Weather Index-based Insurance for Agricultural Production: A Philippine Case Study. Hayama, Japan: IGES; Los Baños, Laguna, Phiippines: SEARCA.

[6] Mathwave Technologies (2015)

[7] Missouri University Crop Resource Guide (2017)

[8] Neate, P. (2013). Climate-Smart Agriculture Success Stories from Farming Communities Around the World. Available from http://publications.cta.int

[9] PAGASA (2017). Isabela Climate Data

[10] Philippine Crop Insurance Corporation (2011). 2011 Annual Report.

[11] Philippine Statistics Authority. (2017). RICE and CORN Situation and Outlook, July 2017 Round. Special Release, Philippine $\begin{array}{lllll}\text { Statistics } & \text { Authority. } & \text { Retrieved } & \text { November }\end{array}$ https://www.psa.gov.ph/sites/default/files/SR\%20Rice\%20and\%20Corn\%20Situation\%20and\%20Outlook\%20July\%202017\%20Roun d.pdf

[12] Schaefer L. and Waters, E. (2016). Climate Risk Insurance for the Poor and Vulnerable: How to Effectively Implement the Pro-Poor Focus of Insuresilience. Munich Climate Insurance Initiative.

[13] Villaver, J.P. and Agan, E. (2019). Agronomic Response of Sweet Corn (Zea mays L. var rogusa) to Fermented Agar-agar (Eucheuma cottonii) and Methods of Applications. International Journal of Science and Management Studies (IJSMS) Vol 2 Issue 5,67-73. 